\title{
Additional Tables
}

Table A

Count of bilingual participants agreeing and not agreeing on second language skills items.

\begin{tabular}{|l|l|c|}
\hline Skills & Agree & Don't Agree \\
\hline Carry on normal conversation in L2 & 19 & 0 \\
\hline Watch television shows in L2 & 19 & 0 \\
\hline Listen to music in L2 & 19 & 0 \\
\hline Read and comprehend questions in L2 & 19 & 0 \\
\hline Read books or articles in L2 & 19 & 0 \\
\hline No problems in understanding L1 speaker & 18 & 2 \\
\hline Carry on a discussion in L2 & 17 & 3 \\
\hline Love speaking L2 & 16 & 13 \\
\hline Explain difficult situation in L2 & 15 & 7 \\
\hline Answer difficult questions in L2 & 12 & 9 \\
\hline Think in L2 & 11 & 11 \\
\hline Speak to myself in L2 & 10 & \\
\hline Write in L2 & 5 & \\
\hline Make no/ almost no mistakes in L2 & & \\
\hline Dream in L2 & & \\
\hline
\end{tabular}


Table B

Count of bilingual participants agreeing and not agreeing on second language switching items.

\begin{tabular}{|l|l|l|}
\hline \multicolumn{1}{|c|}{ Switching } & Agree & Don't \\
\hline I'm sometimes in a tip of the tongue state & Agree \\
\hline I sometimes can't get the right word & 16 & 3 \\
\hline I use a different language when I do not remember a word & 14 & 5 \\
\hline I often use different languages intermixed & 13 & 6 \\
\hline I often use different languages intermixed without noticing & 9 & 10 \\
\hline I sometimes speak in a language that my dialogue partner doesn't & 5 & 14 \\
\hline understand & & \\
\hline
\end{tabular}

